\title{
Correction to: Photo-reactivity of dissolved organic carbon in the freshwater continuum
}

\author{
Balathandayuthabani Panneer Selvam ${ }^{1} \cdot$ Jean-François Lapierre ${ }^{2} \cdot$ Ana R. A. Soares $^{1} \cdot$ David Bastviken $^{3}$. \\ Jan Karlsson ${ }^{4}$. Martin Berggren ${ }^{1}$
}

Published online: 26 February 2020

(c) The Author(s) 2020

\section{Correction to: Aquatic Sciences (2019) 81:57 https://doi.org/10.1007/s00027-019-0653-0}

The original publication of this paper contains mistakes in Fig. 3 and in the captions of Fig. 3, Fig. S1 and Fig. S2. In Fig. 3 the values on the y axis appear wrong. The captions of Fig. 3 and Figs. S1-S2 incorrectly include a headwater stream category with a mixture of forest and mire in the catchments. The mentioning of this "mixed" headwater category should be ignored because it is not represented in the figures.

The correct Fig. 3 is shown in this paper.

Open Access This article is distributed under the terms of the Creative Commons Attribution 4.0 International License (http://creativeco mmons.org/licenses/by/4.0/), which permits unrestricted use, distribution, and reproduction in any medium, provided you give appropriate credit to the original author(s) and the source, provide a link to the Creative Commons license, and indicate if changes were made.

Publisher's Note Springer Nature remains neutral with regard to jurisdictional claims in published maps and institutional affiliations.

The original article can be found online at https://doi.org/10.1007/ s00027-019-0653-0.

Martin Berggren

martin.berggren@nateko.lu.se

1 Department of Physical Geography and Ecosystem Science, Lund University, Lund, Sweden

2 Département de sciences biologiques, Université de Montréal, Montréal, Canada

3 Department of Thematic Studies, Tema Environmental Change, Linköping University, Linköping, Sweden

4 Department of Ecology and Environmental Sciences, Umeå University, Umeå, Sweden 
Fig. 3 The DOC degradation rate per unit irradiation energy absorbed (PD- $\mathrm{E}_{\mathrm{w}}$ ) variation in forest headwater streams $(\mathrm{n}=20)$ mire headwater streams $(n=8)$, lakes $(n=23)$, intermediate rivers $(n=4)$ and river mouths $(n=10)$. Outliers were removed for clarity of the plot. Lack of shared letters indicate significant $(2$-tail $p<0.05)$ difference between the different aquatic ecosystems

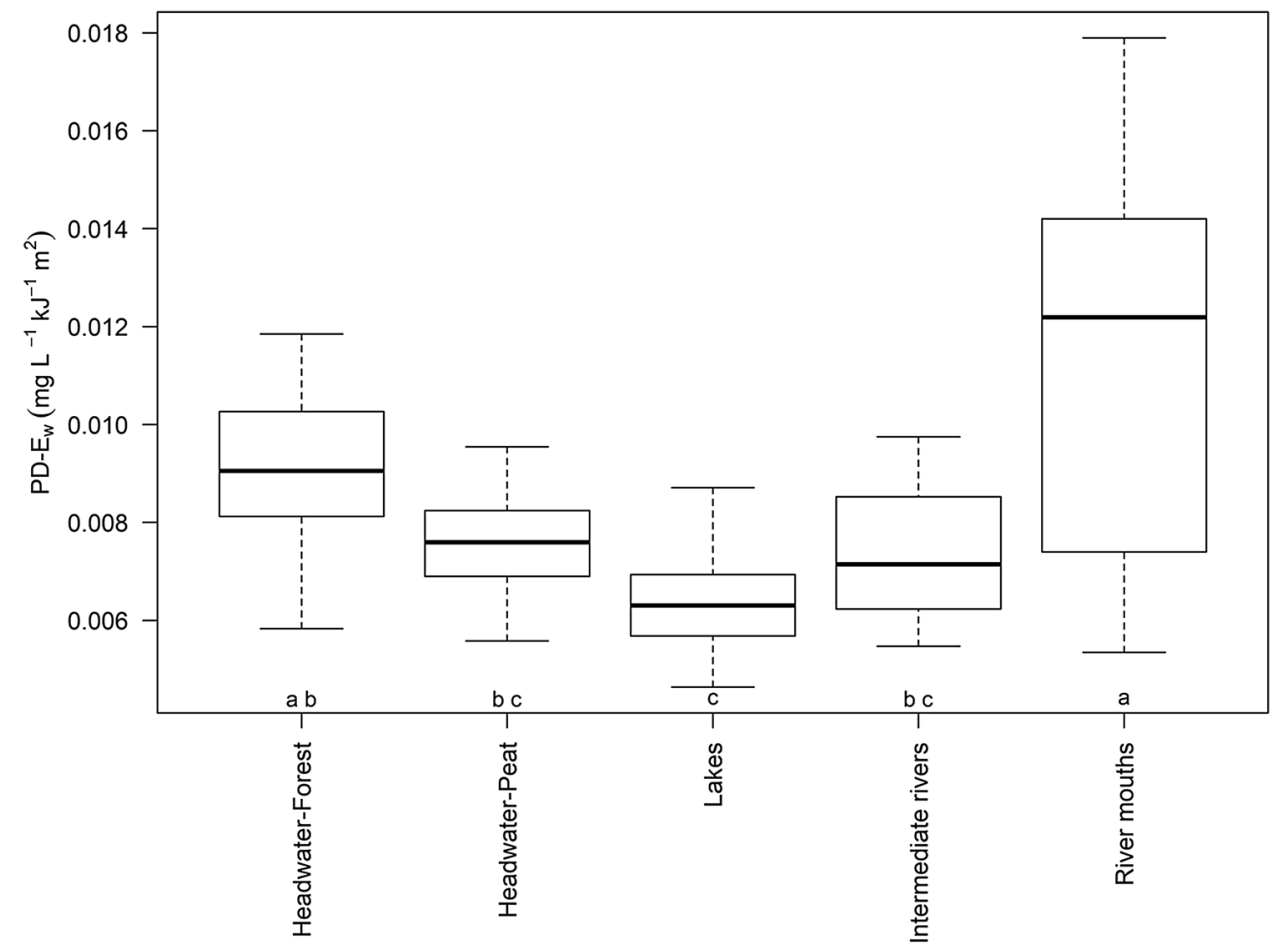

